pag

Business School

WORKING PAPER SERIES

Working Paper

2014-126
Interdependency and Spillover during the Financial Crisis of 2007 to 2009 Evidence from High Frequency Intraday Data

Faten Ben Slimane

Mohamed Mehanaoui

Irfan A. Kazi

http://www.ipag.fr/fr/accueil/la-recherche/publications-WP.html

IPAG Business School

184, Boulevard Saint-Germain

75006 Paris

France 


\title{
Interdependency and Spillover during the Financial Crisis of 2007 to 2009 - Evidence from High Frequency Intraday Data
}

\author{
Faten Ben Slimane ${ }^{\mathrm{a}^{*}}$, Mohamed Mehanaoui $^{\mathrm{b}}$, Irfan A. Kazi ${ }^{\mathrm{bc}}$ \\ ${ }^{a}$ Champagne School of Management, Troyes, France \\ ${ }^{b}$ IPAG Business School, Paris, France \\ ${ }^{c}$ Paris West University Nanterre La Défense, Nanterre, France
}

\begin{abstract}
The paper examines the intraday dynamics and volatility transmission among three European stock markets: Germany, France, the UK during the financial crisis of 2007-to-2009. After estimating the structural break date using Bai-Perron (1998, 2003), we analyze the pre-crisis and crisis periods using high frequency five-minute intraday data under the VAR-EGARCH framework. The empirical findings reveal that the interdependence among European markets increased substantially during the crisis period, pointing towards shift contagion. In addition, the results show that the German stock market strongly influences stock returns and volatility in France and the UK for all periods, while the reverse hold true but is mostly irrelevant. These findings have important implications for both policymakers and investors.
\end{abstract}

Keynotes: Volatility spillover, Global financial crisis, High frequency data

JEL: G15

*Corresponding author : faten.benslimane@get-mail.fr 


\section{Introduction}

During the last 30 years, financial markets have become increasingly interdependent. This trend, evident in both developed and developing countries, resulted in a gradual liberalization of capital movements, deregulation of financial markets and new technologies. These developments affected the evolution of financial markets and contributed to an increase in the interaction/interrelationship among markets (e.g. Lucey and Muckley, 2011; Beine, Cosma and Vermeulen, 2010). As a consequence, domestic markets are becoming less isolated and react almost immediately to new information from international markets. The international linkages among the markets are likely to impact investors negatively, especially during financial turmoil, whereas financial diversification can lead to benefits for investors. Thus, understanding the nature of stock market linkages better is important for investors, regulators, and policymakers.

This paper focuses on an empirical analysis of the interdependence and volatility dynamics of three stock markets: France, Germany, and the UK during the recent global financial crisis of 2007-to-2009. We study volatility transmission during the pre-crisis and crisis periods.

Studies on the interdependence and volatility transmission among international markets during financial crises are now more frequent in the financial literature. Focusing on the financial crisis of 2007-to-2009, Chudik and Fratzscher (2011) analyze the role of the reduction in liquidity conditions of 26 advanced and emerging economies during the financial crisis. Tong and Wei (2008) explain stock price changes following the crisis, while Bekaert et al. (2011) investigate the presence of cross-border contagion in global equity markets during the crisis.

In terms of methodological approach, the GARCH model introduced by Bollerslev (1986) has been widely applied to stock markets. Nelson (1991) proposes an extension by introducing the exponential GARCH model $(\mathrm{EGARCH})$ to capture the leverage effect originally noted by Black (1976), according to which there is an asymmetric response of volatility to positive and negative shocks. Koutmos and Booth (1995), Braun et al. (1995), Kroner and Ng (1996), and Engle and Cho (1999) propose an extension to Nelson's model by providing a bi-variate EGARCH model to study asymmetry in the volatility transmission mechanism. This model attracted extensive research on the volatility transmission in the context of the Asian financial 
crisis and the 2007-2009 crisis (see for example Bhar et al. (2009), In et al. (2001), Iwatsubo et al. (2007), and Morales et al. (2011) among many others).

However, much of the empirical work on stock exchange volatility transmission and interdependence uses daily data and either ignores the same day effect or does not model the simultaneity. With the emergence of High-Frequency-Data (HFD), the analysis of financial markets can yield more accurate results ${ }^{1}$.

This paper contributes to the existing literature in three ways. First, contrary to most prior work, we use high frequency five-minute intraday data to study the volatility interaction among three European equity markets. Moreover, the study also takes into account strong intraday seasonality observed in intraday data. Second, we apply robust econometric techniques notably Bai and Perron test $(1998,2003)$ to date the crisis and distinguish between the crisis and the calm period. Third, our paper extends research on volatility spillover, especially the work of Koutmos (1996) and Kanas (1998), by employing a bi-variate vector autoregressive exponential GARCH (VAR-EGARCH) framework to study market volatility spillover.

The paper is organized as follows. Section 2 presents the econometric methodology used in the study. Section 3 describes the data. Section 4 summarizes the empirical results. Section 5 concludes.

\section{Methodology}

For the empirical analysis, we conduct our study in two stages. First, we apply the Bai and Perron $(1998,2003)$ to identify the structural break in our daily frequency time series data of the Standard \& Poor 500 index (S\&P 500). Second, we apply a bivariate VAR-EGARCH model to our deseasonalized standardized high frequency data ${ }^{2}$ to study the spillover dynamics before and after the structural break date. We elaborate on each of these techniques as follows:

\footnotetext{
${ }^{1}$ According to the SEC, "High frequency trading is a dominant component of the current market structure and is likely to affect all aspects of its performance" (See SEC 2010, p.45)

${ }^{2}$ Deseasonalization of the data was performed using the Flexible Fourier Form (FFF). For more detail a separate appendix may be requested from the authors.
} 


\subsection{Identification of Structural Break}

Using Bai and Perron $(1998,2003)^{3}$ (BP) involves regressing the variable of interest on a constant and then testing for breaks within that constant. Therefore the null hypothesis of no structural break is tested against a certain number of breaks. In our case, Bai and Perron (1998, 2003) may be presented as:

$$
\mathrm{P}_{\mathrm{t}}=\theta_{\mathrm{k}}+\varepsilon_{\mathrm{t}} \quad \mathrm{t}=\mathrm{Tk}-1+1, \ldots \ldots . \mathrm{Tk}, \mathrm{k}=1, \ldots, \mathrm{m}+1
$$

where $\mathrm{Pt}$ is the stock market price index at time $\mathrm{t}, \theta_{\mathrm{k}}$ is the mean of the price in the kth regime and $\mathrm{m}$ represents the length of the time series, and $\varepsilon_{\mathrm{t}}$ represents the error term. The BP procedure requires two parameters for implementation: a minimum number of observations between breaks and a maximum number of possible breaks. More details on the test appear in the Bai and Perron studies (1998, 2003).

\subsection{Bi-variate VAR EGARCH}

The model postulated to describe the filtered returns process is the bi-variate vector autoregressive exponential GARCH (VAR-EGARCH) model.

$$
\begin{aligned}
& R_{i, t}=\beta_{i, 0}+\sum_{j=1}^{n} \sum_{p=1}^{2} \beta_{i, j} R_{j, t-p}+\varepsilon_{i, t} \\
& \left(\begin{array}{l}
\varepsilon_{1, t} \\
\varepsilon_{2, t}
\end{array}\right) \mid I_{t-1} \square N\left(0, H_{t}\right) \text { where } H_{t}=\left(\begin{array}{ll}
h_{1, t} & h_{12, t} \\
h_{12, t} & h_{2, t}
\end{array}\right)
\end{aligned}
$$

where $I_{t-l}$ contains the information set through period $\mathrm{t}-1$, and the diagonal elements of the conditional variance $H_{t}$ are:

$$
\sigma_{i, t}^{2}=h_{i, t}=\exp \left\{\alpha_{i, 0}+\sum_{j=1}^{n} \alpha_{i, j}\left(\left|Z_{j, t-1}\right|-E\left|Z_{j, t-1}\right|+\gamma_{i, j} Z_{j, t-1}\right)+\delta_{i} \operatorname{Ln}\left(\sigma^{2}{ }_{i, t-1}\right)\right\} \text { for } \mathrm{i}, \mathrm{j}=1, \ldots \mathrm{n}
$$

where $\mathrm{Z}_{\mathrm{i}, \mathrm{t}}=\varepsilon_{\mathrm{i}, \mathrm{t}} / \sigma_{\mathrm{i}, \mathrm{t}}$ is the standardized innovation and $\mathrm{E}\left|\mathrm{Z}_{\mathrm{j}, \mathrm{t}-1}\right|=\sqrt{2 / \pi}$ and the off-diagonal elements are given by $\sigma_{\mathrm{i}, \mathrm{j}, \mathrm{t}}=\rho_{\mathrm{i}, \mathrm{j}} \sigma_{\mathrm{i}, \mathrm{t}} \sigma_{\mathrm{j}, \mathrm{t}} \quad \mathrm{i} \neq \mathrm{j}$

Equation (2) describes the returns $R_{i, t}$ of the fourth indexes as a vector autoregressive (VAR) where the conditional mean in each market is a function of past own returns as well as crossmarket past returns.

\footnotetext{
${ }^{3}$ This methodology is preferred on the ground that it lets the data speak of itself compared to the traditional methods of first identifying a break based on certain experience or event and then checking for its significance.
} 
The conditional variance at time $t$ is given in (3). Each of the four $\alpha_{i, j}$ coefficients plays a specific role: $\alpha_{i, j}$ with $i=j$ captures the effect of the magnitude of a lagged innovation on the conditional variance and when $i \neq j$ the coefficient captures the size and sign effect of a shock to market $\mathrm{j}$ on market $\mathrm{i}$.

The term $\gamma$ captures the effect of the sign of a lagged innovation on the conditional variance, i.e. the leverage effect (Black (1976), Christie (1982)). If $\gamma_{\mathrm{j}}$ is negative and statistically significant, then we have an asymmetric response, i.e. if $\gamma_{\mathrm{j}}$ and $\mathrm{Z}_{\mathrm{i}, \mathrm{t}-\mathrm{are}}$ aregative, the effect of the shock will be larger than if it is positive. The last term $\delta$ in the conditional variance is a measure of persistence.

\section{Data, basic statistics and analysis}

For empirical analysis, we use two different data sets. First, we use the S\&P 500 daily data index from $01 / 01 / 2004$ to $31 / 12 / 2010$ to identify the structural break in the time series. This series is obtained from DataStream.

Second, we use high frequency five-minute stock market price data for three markets; namely CAC40 (France), DAX30 (Germany), and FTSE100 (UK) from July 1, 2008 to November 28, 2008 to provide a deeper insight into the spillover dynamics before and after the structural break date obtained at the first stage of our analysis. High frequency data is obtained from Tick Data and consists of 108 trading days and 10710 observations for each series. The markets under study open and close at the same time, i.e. 9.30 CET and 17.30 CET. Therefore we do not encounter the overlapping problem in our study.

We clean the high frequency stock price data for outliers and other anomalies before converting them into continuously compounded returns ${ }^{4}$. If needed, we apply linear interpolation to replace solitary five-minute price quotes to obtain periodical data as required by the Flexible Fourier Form. In addition, following Andersen et al. (2000), we delete the 9.00-9.05 CET return interval to avoid statistical inference ${ }^{5}$.

Table 1 summarizes descriptive statistics for the HFD, categorized under whole period (from July 1, 2008 to November 28, 2008), pre-crisis period (from July 1, 2008 to September 11, 2008), and during the crisis period (from September 12 to November 28, 2008). The division

\footnotetext{
${ }^{4}$ We calculate continuously compounded returns using the equation Ri,t $=100 \mathrm{x}(\operatorname{lnPi}, \mathrm{t}-\operatorname{lnPi}, \mathrm{t}-1)$ where Ri,t is the return for the stock market $\mathrm{i}$ at time $\mathrm{t}, \ln \mathrm{Pi}, \mathrm{t}$ is the $\log$ of the stock price at time $\mathrm{t}$, and $\ln \mathrm{Pi}, \mathrm{t}-1$ is the $\log$ of the laged value of the stock price at time t.

${ }^{5}$ Andersen et al. (2000) highlight relatively high average return volatility in the first five-min return interval of the day in comparison with any other 5-min interval.
} 
of data between the pre-crisis and crisis is based on the structured break test of Bai and Perron (1998, 2003). As expected, all the returns are positive for the period before the crisis but negative during the crisis episode. We observe a similar behavior for standard deviations. Note that the skewness coefficients are positive for France and Germany but not the UK before the crisis. All kurtosis coefficients are greater than three and rise substantially during the crisis period. Finally, the Jacque-Bera test rejects the normality for the three markets for all subsamples.

Figure 1 illustrates clearly the strong structure of the volatility estimated by the absolute returns ${ }^{6}$. Indeed, the intra-daily volatility shows the U-shape identified for most of the markets and suggested by the model of Admati and Pfleiderer (1988): a strong volatility at the beginning and at the end of the trading session ${ }^{7}$. This one falls again to a low level until 14.00 CET and then the activity in the market accelerates significantly with peaks between 14.00 and 15.00 CET. The recurring character of this volatility behavior inside the day of exchange is illustrated via the correlative structure of autocorrelation of absolute and deseasonalized returns (Figure 2). The autocorrelations of the absolute returns on 10 days present systematic peaks for lags which correspond in the whole days. This shows the presence of seasonal structures in our intra-daily data. In line with Andersen and Bollerslev $(1997,1998)$ and with Andersen et al. (2000), and in order to avoid potential biases, the series of intraday returns have to be deseasonalized.

As we observe, the Flexible Fourier Form (FFF) representation reduced the intraday periodicity considerably. Figure 2 of the correlograms of both deseasonalized and standardized absolute returns shows a significant decay in serial correlation. Therefore, the standardized returns reduce the risk of spurious causality. Once the data are deseasonalized and combined in order to remove the periodicity, we obtain contemporaneous five-minute filtered returns.

\footnotetext{
${ }^{6}$ Following the literature, we retain the absolute return $|\mathrm{Rt}, \mathrm{n}|$ as measure of volatility since the autocorrelation of $|\mathrm{Rt}, \mathrm{n}|$ is higher than $\mathrm{Rt}_{\mathrm{n}}{ }^{2}$ and there is more structure to study. For more information see Taylor J., and Xu X. (1997) and Taylor (1986)

${ }^{7}$ The intraday volatility pattern of the others periods is not reported in order to save space but they can be made available on requests to the author.
} 


\section{Empirical results and discussion}

\subsection{Bai-Perron Procedure}

Our approach is to first determine the structural break date using the Bai and Perron (1998, 2003) with one break i.e. two regimes to identify the crisis and pre-crisis period for the dates 01/01/2004 to 31/12/2010. Most of the research articles using S\&P daily data identify 15th of September 2008 as the structural break date. In our case, we are able to discover the structural break on 12th of September 2008. It should be noted that 13th and 14th September are Saturday and Sunday respectively and on 15th September 2008 Lehman Brothers officially announced itself bankrupt and filed for bankruptcy protection. Results of the break point are given below.

\begin{tabular}{|c|c|c|}
\hline Breakpoint & $\begin{array}{c}\text { Lower } \\
95 \%\end{array}$ & $\begin{array}{c}\text { Upper } \\
95 \%\end{array}$ \\
\hline 2008:09:12 & $2008: 08: 21$ & $2008: 11: 10$ \\
\hline
\end{tabular}

\subsection{Bi-variate VAR EGARCH Specification}

Before proceeding to the estimation stage we need to fit the best of bi-variate VAR $(\mathrm{k})$ $\operatorname{EGARCH}(p, q)$ models to our data series. As indicated in Tables 2,3 and 4, we chose VAR (1) EGARCH $(1,1)$ for all three bivariate relations for the crisis and pre-crisis period except for the CAC40-DAX30 pair for the pre-crisis period where a $\operatorname{VAR}(2) \operatorname{EGARCH}(1,1)$ seems more appropriate $^{8}$. The variance equation of the model exhibits an acceptable fit to the data with all parameters. Indeed the GARCH and asymmetric terms are almost significant for all the pairs at a one percent significance level. Moreover, the p-values of the Ljung-Box statistics, $Q(20)$ and $\mathrm{Q}^{2}(20)$, are greater than one percent for all market pairs, and therefore we can accept the null hypothesis of no autocorrelation up to order 20 for both standardized residuals and squared standardized residuals. According to the VAR equation, the own lagged returns as well as the lagged returns $(\beta i, j)$ of other markets are significant for almost all the market at the minimum of a 10 percent significance level. However, the DAX30 seems to influence the CAC40 and FTSE100 with higher magnitude while the reverse is also true but with a lesser magnitude. Concerning CAC40 and FTSE100, we observe that CAC40 is influenced by FTSE100 for both the pre-crisis and crisis periods whereas for the reverse the results are not significant.

\footnotetext{
${ }^{8}$ The lag was chosen based upon Shwartz and AIC Information criteria.
} 


\subsection{Estimation of Bivariate VAR EGARCH}

Tables 3, 4 and 5 give the estimates of a significant return spillover between the markets. These findings confirm previous research with similar results, especially at an intraday level (e.g. Hussain, 2011). Moreover, our results show that the magnitude of the return spillover is more important at the first lagged term than the second.

Comparative analysis of the results of pre-crisis and crisis periods reveal that the level of correlation of returns between the markets increased significantly after the break date except for the CAC 40 and DAX 30 pair where the correlations are relatively constant with a coefficient of correlation $(\rho)$ of 0.83 . These results confirm the findings of Forbes and Rigobon (2002) and Ahlgren and Antell (2010) that, following a crisis or a shock to one country, we can observe a significant increase in cross-market linkages/correlations.

The results of conditional volatility also reveal similar results for volatility transmission between the markets. We observe that before the bankruptcy of Lehman Brothers (15/09/2008) there was volatility transmission from the FTSE 100 to the CAC40 index, from the DAX30 to the CAC40 index, and from the DAX30 to the FTSE100 index. During the crisis period, we observe a similar tendency but with a higher magnitudes of volatility transmission. The results show that the volatility spillover from the DAX 30 to the CAC 40 is around 11 percent, from the CAC 40 to the FTSE 100 it is around 22.5 percent, and from the DAX30 to the FTSE100 it is around 18 percent. Therefore, we find strong evidence that the markets under study are interdependent and the German stock market overreacts on a shorter horizon compared to the other two markets. One possible explanation for this over reaction could be due to the overall composition of the financial and real channels of transmission. Finally, during the global financial crisis, there is a higher tendency toward shift contagion.

We find that the coefficients of asymmetry $\left(\gamma_{\mathrm{i}, \mathrm{j}}\right)$ are significant for the crisis period. The asymmetry effect exists for almost all the countries during the crisis and pre-crisis periods. However, we find one instance where there is positive asymmetric effect that is significant for the turmoil period. This result is not surprising as, during the turmoil period, the good news may have a bigger impact than the negative news compared to the calm period.

The volatility persistence coefficients $\left(\delta_{\mathrm{i}}\right)$ are highly significant and very nearly reach one during the crisis period. This result is expected as the markets are in a continuous process of turbulence and the clustering phenomenon is observed. 


\section{Conclusion}

This article extends the existing literature on volatility transmission during the global financial crisis by applying VAR EGARCH methodology on high frequency five-minute intra-day data for three major European economies. After deseasonalizing our data we segment it into two parts i.e. pre-crisis and crisis periods, based upon the break date of $12 / 09 / 2008$, estimated using the Bai-Perron $(1998,2003)$ procedure. This break date is very close to the date of Lehman Brothers' default of 15/09/2008. Specially, to focus on intraday return and volatility transmission dynamics, we take a window of two months before and after the structural break date. VAR EGARCH estimates provide interesting insight into interdependence structures, return and volatility spillover during the crisis period. First, we conclude that the three indices, the DAX 30, CAC 40, and FTSE 100, are highly correlated to one another for the entire period of study and these correlations become even more important during the turmoil period, giving rise to the phenomenon of shift contagion. This argument is further supported by the findings of Mun and Brooks (2012). Second, we conclude that each market influences the other in the very short run, but the German stock market plays the most active role by influencing the other two markets. Lastly, we observe a similar behavior for volatility transmission. Germany may be regarded as the battery for volatility transmission to France and the UK. This argument may be supported by the fact that Germany is regarded as the hub of financial and economic activity in Europe. This result is in line with the results of Chen et al. (2003) and Bialkowski et al. (2006) and has important implications for international portfolio diversification strategy. In particular, international investors and policy makers may want to analyze the volatility and return behavior of local stock markets when there is a negative shock to another stock market.

\section{References}

Admati A. and P. Pfleiderer. (1988). A theory of intraday patterns: volume and price variability. The Review of Financial Studies (1) 3-40

Ahlgren, Niklas and Antell, (2010). Stock market linkages and financial contagion: A cobreaking analysis. The Quarterly Review of Economics and Finance (50) 157-166.

Andersen T. G., and Bollerslev T. (1998). Deutsche Mark-Dollar Volatility: Intraday Activity Patterns, Macroeconomic Announcements, and Longer Run Dependencies. Journal of Finance (53), 219-265.

Andersen T.G., and Bollerslev T. (1997). Intraday periodicity and volatility persistence in financial markets. Journal of Empirical Finance (4) 115-158.

Andersen T.G., Bollerslev T. and Cai J. (2000). Intraday and interday volatility in the Japanese stock market. Journal of International Financial Markets, Institutions and Money, 10 (2), pp.107-130.

Andersen T.G. and Bollerslev T. (2006). Realized Return Volatility, Asset Pricing, and Risk Management. NBER Reporter: Research Summary.

Bai, J. and Perron, P. (1998). Estimating and Testing Linear Models with Multiple Structural Changes. Econometrica (66), 47-78.

Bai, J. and Perron P. (2003). Computation and Analysis of Multiple Structural Change Models. Journal of Applied Econometrics (18), 1-22.

Beine M., A. Cosma and R. Vermeulen (2010). The dark side of global integration: Increasing tail dependence. Journal of Banking \& Finance (34) 184-192. 
Bekaert G., M. Ehrmann, M. Fratzcher and A. J. Mehl (2011). Global crises and equity market contagion. NBER Working Paper (17121).

Bhar R., Nikolova B. (2009). Return, volatility spillovers and dynamic correlation in the BRIC equity markets: An analysis using a bivariate EGARCH framework. Global Finance Journal, Volume 19, Issue 3, Pages 203-218.

Bialkowski J., Bohl M. and Serwa D. (2006). Testing for financial spillovers in calm and turbulent periods. The Quarterly Review of Economics and Finance (46) 397-412.

Black R. (1976). Studies in stock price volatility changes. Proceedings of the 1976 Business Meeting of the Business and Economics Statistics Section. American Statistical Association 177-181.

Bollerslev T. (1986). Generalized autoregressive conditional Heteroskedasticity. Journal of Econometrics (31) 307-327.

Braun, P.A., Nelson, D.B., and Sunier, A.M. (1995). Good News, Bad News, Volatility and Betas. Journal of Finance (50) 1575-1603.

Christie A. (1982). The stochastic behavior of common stock variances- value, leverage, and interest rate Effects. Journal of Financial Economic Theory (10) 407-432.

Chen, C. W. S., Chiang, T. C., and So, M. K. P. (2003). Asymmetrical reaction to US stockreturn news: Evidence from major stock markets based on a double-threshold model. Journal of Economics and Business ( 55) 487-502.

Chudik and Fratzscher (2011). Identifying the global transmission of the 2007-2009 financial crisis in a GVAR model. European Economic Review (55) 325-339.

Forbes K., and Rigobon R. (2002). No contagion, only interdependence: measuring stock market co-movements. Journal of Finance (57), 2223-2261.

Hussain, S.M. (2011). Intraday trading volume and international spillover effects. Research in International Business and Finance (25) 183-194.

In, F., Kim, S., Yoon, J. H., Viney C. (2001). Dynamic interdependence and volatility transmission of Asian stock markets: Evidence from the Asian crisis, International Review of Financial Analysis (10) 87-96.

Iwatsubo, K., Inagaki, K., (2007). Measuring financial market contagion using dually-traded stocks of Asian firms, Journal of Asian Economics (18) 217-236.

Kanas, A. (1998). Linkages between the US and the European equity markets: Further evidence from cointegration tests. Applied Financial Economics (8) 607-614.

Koutmos, G. and G. G. Booth. (1995). Asymmetric volatility transmission in international stock markets. Journal of International Money and Finance (14) 747-62.

Koutmos, G. (1996). Modeling the dynamics interdependence of major European stock markets. Journal of Business Finance and Accounting (23) 975-988.

Kroner, K.F., and Ng, V.K. (1996). Multivariate GARCH Modelling of Asset Returns. Papers and Proceedings of the American Statistical Association, Business and Economics Section 31-46.

Lucey B. M and C. Muckley (2011). Robust Global Stock Market Interdependencies. International Review of Financial Analysis (20) 215-224.

Morales, L., Andreosso-O'Callaghan, B. (2011). Comparative analysis on the effects of the Asian and global financial crises on precious metal markets, Research in International Business and Finance (25) 203-227.

Mun M. and Brooks R. (2012). The roles of news and volatility in stock market correlations during the global financial crisis. Emerging Markets Review (13) 1-7.

Nelson, D.B. (1991). Conditional heteroskedasticity in asset returns: a new approach. Econometrica (59) 347-370.

Taylor J., and Xu X. (1997). The Incremental Volatility Information in One Million Foreign Exchange Quotations. Journal of Empirical Finance (4) 317-340. 
Taylor S.J (1986). Modelling Financial Time Series. J, Willey \& Sons, Chichester

Teulon F., Sahut J.M. and Mili M. (2012). What is the linkage between real growth in the Euro area and global financial market conditions ?, Economics bulletin 32 (3) 24642480.

Tong H. and Wei. S. (2008). Real Effects of the Subprime Mortgage Crisis: Is it a Demand or a Finance Shock?. NBER Working Papers 14205. National Bureau of Economic Research.

Table 1. Summary of statistics of the high frequency 5 minute intra-day stock Index Returns

\begin{tabular}{|c|c|c|c|c|c|c|c|c|c|}
\hline & \multicolumn{3}{|c|}{$\begin{array}{c}\text { Whole Sample } \\
\text { July } 1,2008 \text { to November } 28,2008\end{array}$} & \multicolumn{3}{|c|}{$\begin{array}{c}\text { Pre-Crisis Period } \\
\text { July } 1,2008 \text { to September } 12,2008\end{array}$} & \multicolumn{3}{|c|}{$\begin{array}{c}\text { Crisis Period } \\
\text { September } 13,2008 \text { to November } 28,2008\end{array}$} \\
\hline & RSCAC & RSDAX & RSFTS & RSCAC & RSDAX & RSFTS & RSCAC & RSDAX & RSFTS \\
\hline Mean & -0.002332 & -0.001905 & -0.001426 & 0.000530 & 0.001422 & 0.000463 & -0.005036 & -0.005047 & -0.003211 \\
\hline Median & -0.003149 & -0.003858 & -0.004682 & -0.002501 & 0.000450 & -0.002814 & -0.004013 & -0.009451 & -0.008791 \\
\hline Maximum & 2.768749 & 2.838545 & 2.900669 & 1.132326 & 1.395331 & 1.060863 & 2.768749 & 2.838545 & 2.900669 \\
\hline Minimum & -1.673299 & -1.791665 & -3.044328 & -1.090163 & -1.079340 & -0.842513 & -1.673299 & -1.791665 & -3.044328 \\
\hline Std. Dev. & 0.232476 & 0.243903 & 0.226617 & 0.182200 & 0.185796 & 0.178694 & 0.271532 & 0.288201 & 0.264012 \\
\hline Skewness & 0.103355 & 0.107824 & 0.093690 & 0.071269 & 0.050567 & -0.034998 & 0.122225 & 0.133416 & 0.136466 \\
\hline Kurtosis & 6.938096 & 7.023621 & 12.08220 & 4.948796 & 5.879413 & 4.397209 & 6.305681 & 6.051845 & 11.88740 \\
\hline Jarque-Bera & 6939.780 & 7245.328 & 36825.20 & 827.5778 & 1799.296 & 424.2000 & 2521.581 & 2153.848 & 18144.36 \\
\hline Probability & 0.000000 & 0.000000 & 0.000000 & 0.000000 & 0.000000 & 0.000000 & 0.000000 & 0.000000 & 0.000000 \\
\hline Observations & 10710 & 10710 & 10710 & 5202 & 5202 & 5202 & 5508 & 5508 & 5508 \\
\hline
\end{tabular}

Table 2. VAR (1) EGARCH (1,1) CAC 40 - FTSE 100 Estimates

\begin{tabular}{|c|c|c|c|c|c|c|}
\hline \multirow[b]{2}{*}{ Variable } & \multicolumn{3}{|c|}{ Before 12/09/2008 } & \multicolumn{3}{|c|}{ After 12/09/2008 } \\
\hline & Coeff & Std Error & T-Stat & Coeff & Std Error & T-Stat \\
\hline$\beta_{1,0}$ & 0.0001 & 0.0013 & 0.0594 & $-0.0068 * *$ & 0.0031 & -2.2115 \\
\hline$\beta_{1,1}$ & $-0.0980^{* * * *}$ & 0.0203 & -4.8173 & $-0.1269^{* * *}$ & 0.019 & -6.6757 \\
\hline$\beta_{1,2}$ & $0.1253^{* * *}$ & 0.023 & 5.4433 & $0.1255^{* * *}$ & 0.0184 & 6.8089 \\
\hline$\beta_{2,0}$ & 0.0003 & 0.0018 & 0.1959 & $-0.0053^{*}$ & 0.0029 & -1.8372 \\
\hline$\beta_{2,1}$ & $0.0409^{* *}$ & 0.02 & 2.0482 & $0.0340^{*}$ & 0.0187 & 1.8172 \\
\hline$\beta_{2,2}$ & -0.0081 & 0.0223 & -0.3648 & 0.0118 & 0.017 & 0.6939 \\
\hline$\alpha_{1,0}$ & $-0.6520^{* * *}$ & 0.0788 & -8.2732 & $-0.1839 * * *$ & 0.0306 & -6.017 \\
\hline$\alpha_{1,1}$ & $0.0732^{* * * *}$ & 0.0207 & 3.5432 & $0.1598^{* * *}$ & 0.0191 & 8.3607 \\
\hline$\alpha_{1,2}$ & $0.1141 * * *$ & 0.0213 & 5.3674 & $0.0845^{* * *}$ & 0.0149 & 5.6717 \\
\hline$\alpha_{2,0}$ & $-0.5698 * * *$ & 0.0062 & -91.7875 & $-0.1912^{* * * *}$ & 0.0299 & -6.4019 \\
\hline$\alpha_{2,1}$ & $0.0558 * * *$ & 0.0171 & 3.2598 & $0.2253 * * *$ & 0.0196 & 11.4981 \\
\hline$\alpha_{2,2}$ & $0.1050^{* * *}$ & 0.0203 & 5.1841 & $0.0460 * * *$ & 0.0146 & 3.1477 \\
\hline$\gamma_{12}$ & $0.5602 *$ & 0.3016 & 1.8571 & $-0.0938 * * *$ & 0.033 & -2.8477 \\
\hline$\gamma_{21}$ & $-0.4119^{* *}$ & 0.1643 & -2.5075 & $-0.2250^{* * *}$ & 0.0828 & -2.7162 \\
\hline$\delta_{1}$ & $0.8087 * * *$ & 0.0229 & 35.2466 & $0.9287 * * *$ & 0.0115 & 80.783 \\
\hline$\delta_{2}$ & $0.8344 * * *$ & 0.0024 & 353.2126 & $0.9278^{* * *}$ & 0.011 & 84.6729 \\
\hline$\rho$ & $0.8060^{* * *}$ & 0.0046 & 174.3189 & $0.8329 * * *$ & 0.0036 & 232.3012 \\
\hline $\mathrm{Q}_{\mathrm{CAC}}(20)$ & 27.60 & p-value 0.119 & & 24.612 & p-value 0.326 & \\
\hline $\mathrm{Q}_{\mathrm{FTSE}}(20)$ & 29.155 & p-value 0.098 & & 26.054 & p-value 0.128 & \\
\hline $\mathrm{Q}^{2}{ }_{\mathrm{CAC}}(20)$ & 25.661 & p-value 0.130 & & 21.739 & p-value 0.344 & \\
\hline $\mathrm{Q}_{\mathrm{FTSE}}^{2}(20)$ & 21.525 & p-value 0.202 & & 21.441 & $\mathrm{p}$-value 0.550 & \\
\hline
\end{tabular}

Note: $* * *, * * *$ represent statistical significance at $10 \%, 5 \%$ and $1 \%$ respectively. 
Table 3. VAR (1) EGARCH (1,1) DAX 30 - FTSE 100 Estimates

\begin{tabular}{|c|c|c|c|c|c|c|}
\hline \multirow[b]{2}{*}{ Variable } & \multicolumn{3}{|c|}{ Before 12/09/2008 } & \multicolumn{3}{|c|}{ After $12 / 09 / 2008$} \\
\hline & Coeff & Std Error & T-Stat & Coeff & Std Error & T-Stat \\
\hline$\beta_{1,0}$ & 0.0009 & 0.0025 & 0.3609 & $-0.0051^{*}$ & 0.0031 & -1.667 \\
\hline$\beta_{1,1}$ & 0.0166 & 0.0209 & 0.7939 & $-0.0639 * * *$ & 0.0163 & -3.9165 \\
\hline$\beta_{1,2}$ & 0.0011 & 0.0212 & 0.0508 & $0.0318^{* *}$ & 0.0161 & 1.9744 \\
\hline$\beta_{2,0}$ & 0.0006 & 0.0024 & 0.2618 & -0.0035 & 0.003 & -1.1677 \\
\hline$\beta_{2,1}$ & $0.1516^{* * *}$ & 0.0197 & 7.6869 & $0.0941 * * *$ & 0.0164 & 5.734 \\
\hline$\beta_{2,2}$ & $-0.0915^{* * *}$ & 0.0206 & -4.4342 & $-0.0411 * *$ & 0.0174 & -2.3638 \\
\hline$\alpha_{1,0}$ & $-0.5183^{* * *}$ & 0.0963 & -5.3824 & $-0.0869^{* * *}$ & 0.0141 & -6.1684 \\
\hline$\alpha_{1,1}$ & $0.1373 * * *$ & 0.0208 & 6.5894 & $0.1705^{* * *}$ & 0.0147 & 11.6273 \\
\hline$\alpha_{1,2}$ & 0.0323 & 0.0205 & 1.5715 & 0.0165 & 0.0117 & 1.4082 \\
\hline$\alpha_{2,0}$ & $-0.4229 * * *$ & 0.0792 & -5.3407 & $-0.1270^{* * *}$ & 0.0209 & -6.0909 \\
\hline$\alpha_{2,1}$ & $0.0758 * * *$ & 0.0182 & 4.152 & $0.1795^{* * * *}$ & 0.0161 & 11.1249 \\
\hline$\alpha_{2,2}$ & $0.0859 * * *$ & 0.0209 & 4.109 & $0.0681^{* * *}$ & 0.0123 & 5.53 \\
\hline$\gamma_{12}$ & -0.049 & 0.0754 & -0.6501 & $-0.1301 * * *$ & 0.0393 & -3.3083 \\
\hline$\gamma_{21}$ & -0.1007 & 0.0931 & -1.0824 & $-0.0314^{*}$ & 0.1092 & -1.9881 \\
\hline$\delta_{1}$ & $0.8452 * * *$ & 0.0285 & 29.6699 & $0.9639 * * *$ & 0.0055 & 174.1163 \\
\hline$\delta_{2}$ & $0.8770^{* * *}$ & 0.0228 & 38.4051 & $0.9508^{* * *}$ & 0.0077 & 122.8481 \\
\hline $\mathrm{P}$ & $0.7521 * * *$ & 0.0059 & 127.4695 & $0.7783^{* * *}$ & 0.0051 & 151.5845 \\
\hline $\mathrm{Q}_{\mathrm{DAX}}(20)$ & 29.602 & p-value 0.091 & & 23.048 & $\mathrm{p}$-value 0.112 & \\
\hline $\mathrm{Q}_{\mathrm{FTSE}}(20)$ & 27.648 & $\mathrm{p}$-value 0.150 & & 20.226 & $\mathrm{p}$-value 0.323 & \\
\hline $\mathrm{Q}^{2}{ }_{\mathrm{DAX}}(20)$ & 18.812 & p-value 0.564 & & 12.377 & p-value 0.749 & \\
\hline $\mathrm{Q}^{2}{ }_{\text {FTSE }}(20)$ & 17.303 & p-value 0.627 & & 19.255 & p-value 0.315 & \\
\hline
\end{tabular}

Note: $*, * *, * * *$ represent statistical significance at $10 \%, 5 \%$ and $1 \%$ respectively. 
Figure 1: Intraday volatility pattern in international stock markets

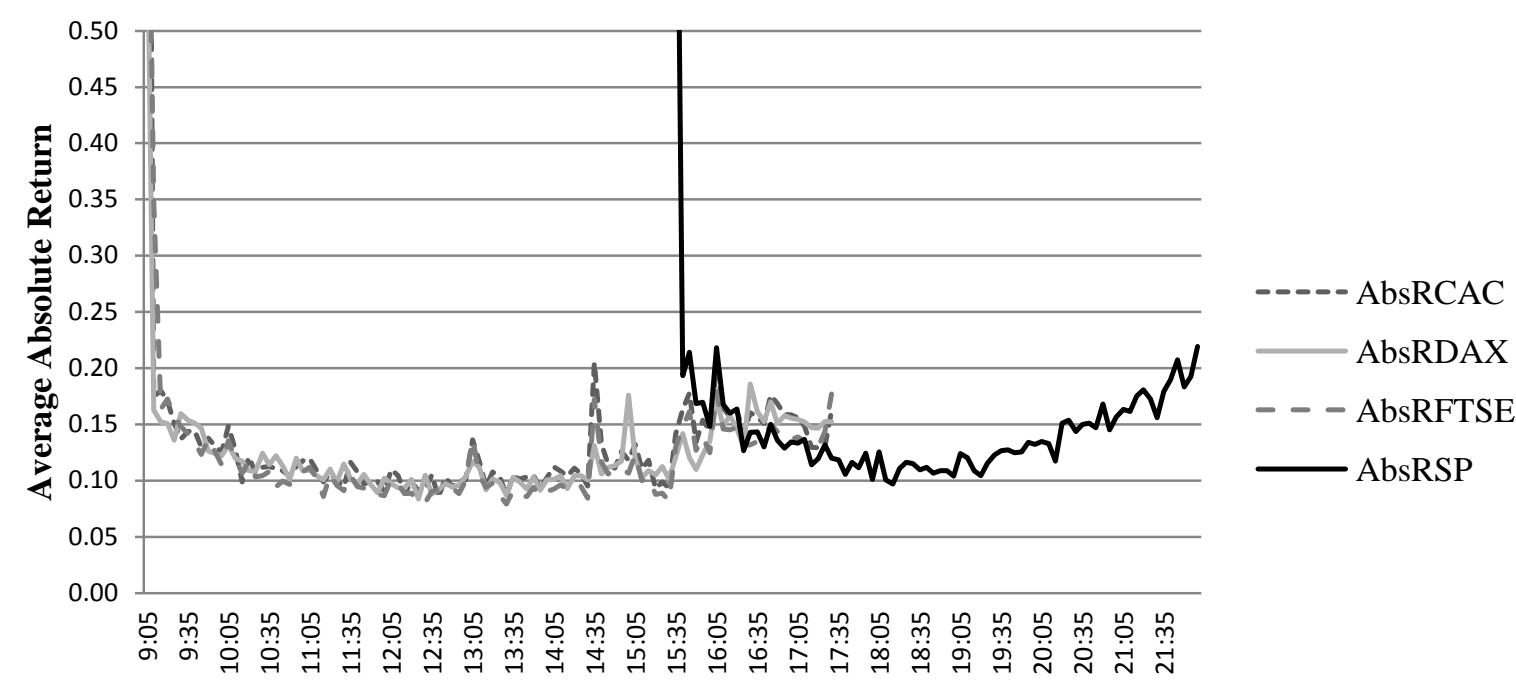

Time (CET)

Note: The graph depicts the average at intervals of five minutes of the returns observed in 2008 for CAC 40, DAX 30, FT100 and SP50

Figure 2: Intraday volatility pattern in international stock markets
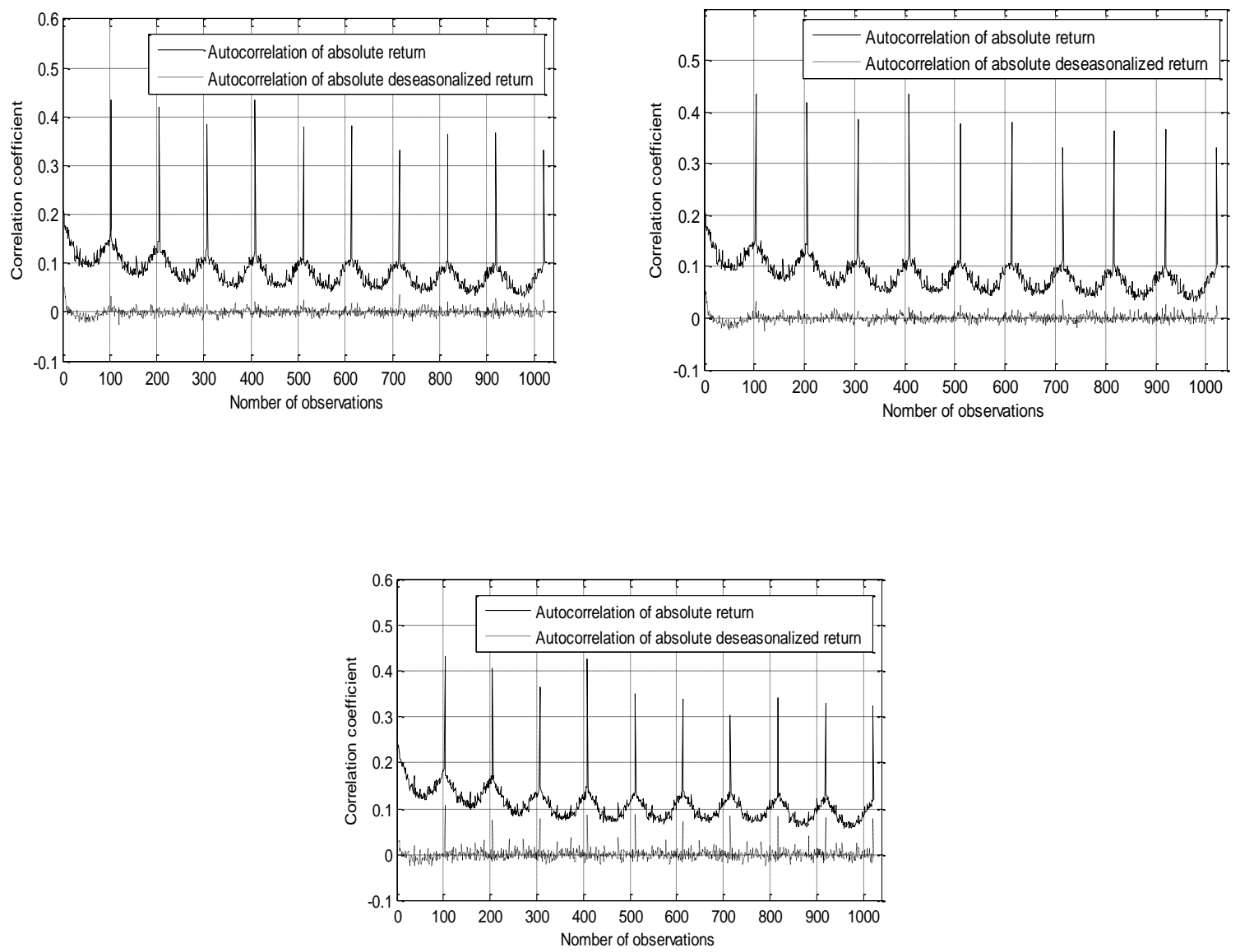

Note: The maximum lag length depicted on x-axis is 10 days for all markets. The solid line depicts the autocorrelations coefficients for absolute returns. The dotted line depicts the autocorrelations coefficients for absolute deseasonalized returns. 